\title{
REVIEW
}

\section{Interleukin role in the regulation of endothelial cell pathological activation}

\author{
Maria Luigia Carbone and Cristina Maria Failla \\ Experimental Immunology Laboratory, IDI-IRCCS, Rome, Italy \\ Correspondence should be addressed to C M Failla: C.Failla@idi.it
}

\begin{abstract}
Interleukins (ILs) are the group of cytokines firstly identified as expressed by leukocytes and playing different immunomodulatory functions. With increasing evidence of a constant crosstalk between leukocytes and endothelial cells in the regulation of immune cell differentiation and activation, a role of ILs also in endothelial cell stimulation and vascular inflammation has been shown. ILs act on endothelial cells both in an autocrine and a paracrine manner. In fact, a cross regulation is present among ILs expressed by different cell types, leading to amplification or blocking of the initial inflammatory signal with the secretion of additional ILs or involvement of other adjacent cells and tissues. Based on selective structural features, ILs can be divided into four major groups, a fifth group comprises ILs that do not fit into any of the other four. Most of the ILs playing a role in endothelial cell activation belong to the IL1-like cytokine group, but the number of ILs involved in vascular inflammation is constantly growing, and a special contribution of IL6, IL8, and IL17 has been underlined. This review aims at presenting current knowledge and at underling missing information about the role of IL in activating endothelial cells in selected pathological settings such as tumours, psoriasis, systemic sclerosis, and viral infection.
\end{abstract}

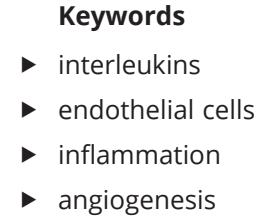

Keywords

- interleukins

- endothelial cells

- angiogenesis

\section{Introduction}

Interleukins (ILs) are the group of cytokines firstly identified as expressed by leukocytes and playing different immunomodulatory functions. In recent years, with increasing evidence of a continuous crosstalk between leukocytes and endothelial cells (ECs) in the regulation of immune cell differentiation and activation, the role of some ILs in EC stimulation and vascular inflammation has been underlined.

Based on selective structural features, ILs can be divided into four major groups: the IL1-like cytokines, the class 1 helical cytokines (IL4-like, $\gamma$-chain, and IL6/IL12like), the class 2 helical cytokines (IL10-like and IL28-like), and the IL17-like cytokines (1). A fifth group comprises ILs that do not fit into any of the four other groups.
IL1-like cytokines are mainly secreted by activated monocytes and macrophages, but they are produced also by other immune (neutrophils, lymphocytes) and nonimmune (keratinocytes, fibroblasts, chondrocytes, ECs, and smooth muscle cells) cell types (2). IL1-like ILs are secreted as precursor proteins that are then proteolytically cleaved to give the active, mature molecule (3). This processing strictly regulates the availability of the effective IL. Class 1 helical cytokines include short- $(\gamma$-chain and IL4-like) and long (IL6/IL12-like)-chain cytokines. They are immunoregulatory molecules that bind to heterodimeric receptors. In some cases, the receptor complex shares a $\gamma$ chain (4). The IL6/IL12-like cytokines act as monomers or heterodimers, composed of disulphide-linked $\alpha$ and $\beta$ 
chains, each signalling through a specific combination of dimerized receptors $(5,6)$. The class 2 helical cytokines, despite structural similarities, display different expression patterns and functions, acting either as antiinflammatory and immunosuppressive proteins or having an immunoregulatory role in the defence against microbial and viral pathogens (7). IL17A and IL17F are the most well-characterized members of the six that compose the IL17-like family. They act both as homodimers and IL17A/IL17F heterodimers. IL17A is produced by activated CD4+ T lymphocytes and innate immune cells (8) and induces inflammatory reactions such as secretion of chemokines and expression of adhesion molecules in receptor-expressing cells (9). The 'non-classified' ILs are cytokines with immunomodulatory actions showing unique structural characteristics or for which no structural information is available so far. This group comprises IL8, taxilin- $\alpha,-\beta$, and $-\gamma$ (TXLNA, TXLNB and TXLNG), IL16, IL32, IL34, and colony-stimulating factor-1 (CSF1).

ILs are strictly interconnected and often one IL can prompt a cell type at secreting additional ILs that, in turn, act on the same cell type or on different cells and tissues, amplifying or blocking the initial IL input. Therefore, to present the role of a single IL in EC activation, it is necessary to consider the pathological context in which it operates and the other ILs present in the same microenvironment.

\section{ILs and their involvement in pathologies where ECs play a prominent role}

It is now fully accepted that acute and chronic inflammatory processes are associated with vascular remodelling. Typical signs of inflammation are increased blood flow, due to vessel dilation or angiogenesis, oedema formation because of increased vessel permeability and altered lymphatic vessels, augmented expression by ECs of adhesion molecules that enable leukocyte interactions with the vessel, and extravasation towards the inflamed tissue. Different pathological conditions are characterized by important tissue inflammation, and ILs play a major role in all these inflammatory processes. An additional component of tissue inflammation is the presence of the senescence-associated secretory phenotype (SASP), activated by senescent cells (10). Diverse ILs are present in the SASP, mainly IL1A, IL1, IL6, and IL8 (11), and they can act on ECs in an autocrine, when secreted by senescent ECs themselves, or in a paracrine manner (12). Table 1 summarizes the ILs known to play a role in EC activation. Below, we reported about the involvement of specific ILs in modulating EC inflammation in pathological conditions, presenting novel concepts that should be considered in future research in the field.

\section{Tumours}

ILs have been associated to cancer since their first characterization, but only in the last decade, they have been associated to tumour angiogenesis. Moreover, role of IL in regulating the presence of inflammatory infiltrate within the tumour tissue has been investigated only recently.

As indicated in Table 1, most of the ILs acting on ECs in an autocrine or a paracrine manner belong to the IL1like cytokine group. IL1B is the founding member, and it represents a major mediator of innate immune reactions. Binding of IL1B to the IL1 receptor (R) 1 induces the enrolment of the IL1R accessory protein (IL1RAP) into a signalling receptor complex that in turn, by recruiting additional adapters such as myeloid differentiation factor 88 (MYD88), IL1R-associated kinase (IRAK), and TNF receptor-associated factor 6 (TRAF6), activates the NFKB and the mitogen-activated protein kinases (MAPKs) pathways. IL1B actions are tightly balanced, and several endogenous inhibitors, such as IL1R antagonist (IL1RA), have been isolated (13). IL1B contributes to vasorelaxation through altering EC responsiveness to nitric oxide and to reduction of endothelial barrier functions (14). IL1B can also act indirectly on ECs by stimulating the production of angiogenic factors. In the tumour microenvironment, expression of IL1B by cancer cells converts the neighbouring vascular endothelium into a pro-inflammatory one (15). Presence of an incremented expression of the inflammatory IL1B in respect to the anti-inflammatory IL1RA leads to stimulating tumour cells, such as melanoma cells, to produce IL8 and IL6 that, in turn, activate ECs $(16,17)$.

The angiogenic switch that characterizes tumour progression towards a more aggressive phenotype is due to an unbalance between pro- and anti-angiogenic factors (18). Considering what was previously reported for IL1B in the tumour environment, the angiogenic switch could be also due to an unbalance in the production of pro- and anti-inflammatory ILs (Fig. 1). This aspect should be better analysed in the future to evaluate the relative importance of ILs or angiogenic factors in the initial phases of tumour angiogenesis.

IL8 is the only cytokine of its group for which a role as pro-angiogenic molecule has been clearly recognized so far, especially in tumour angiogenesis (19). IL8 is also a member of the chemokine family (CXC group) and was 

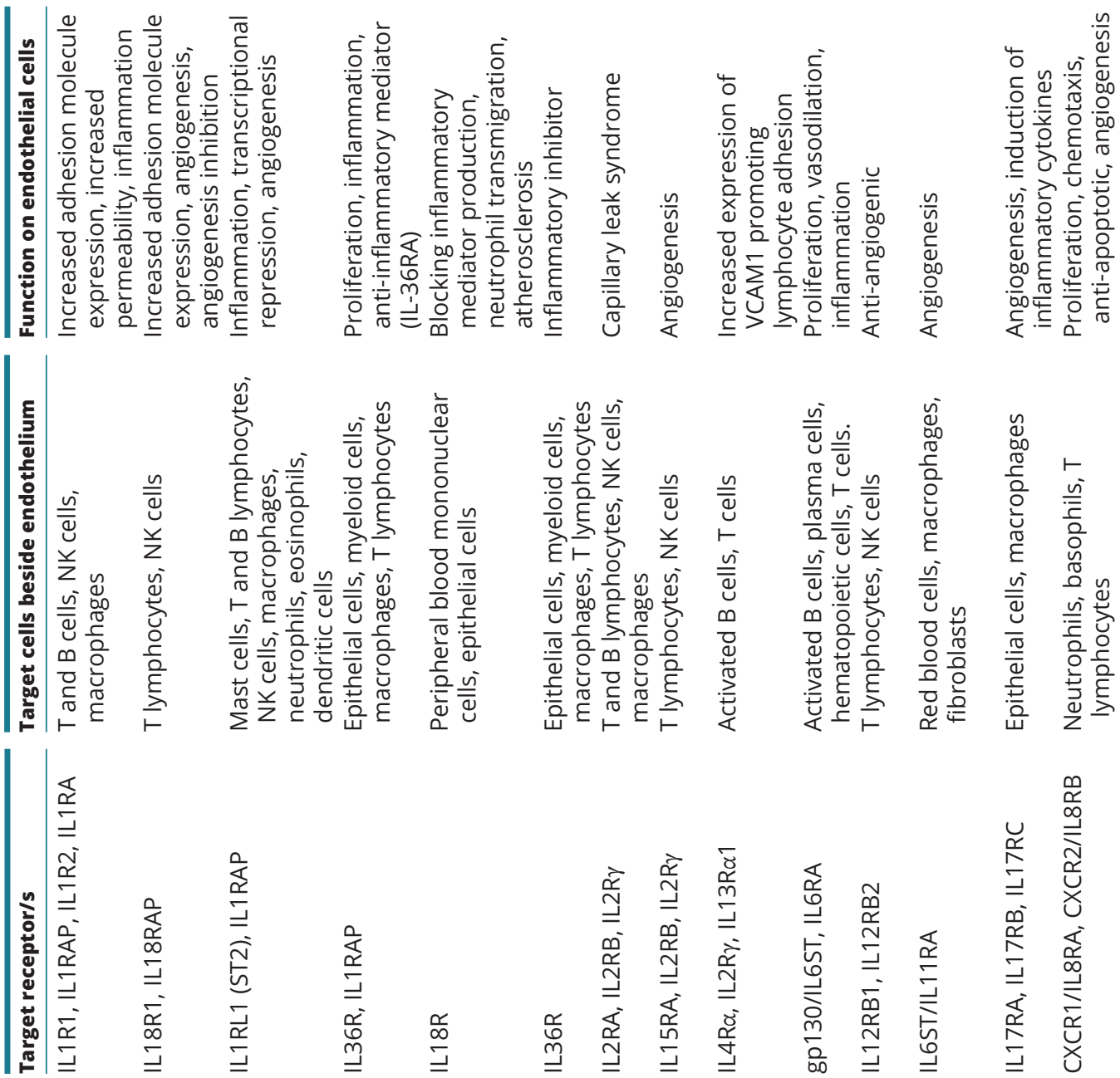

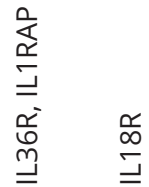
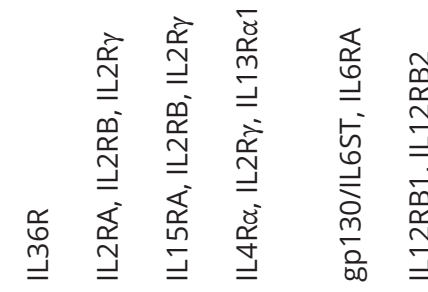

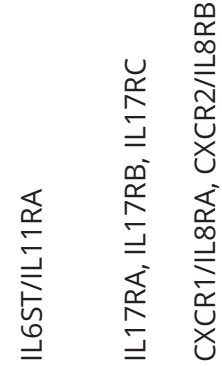
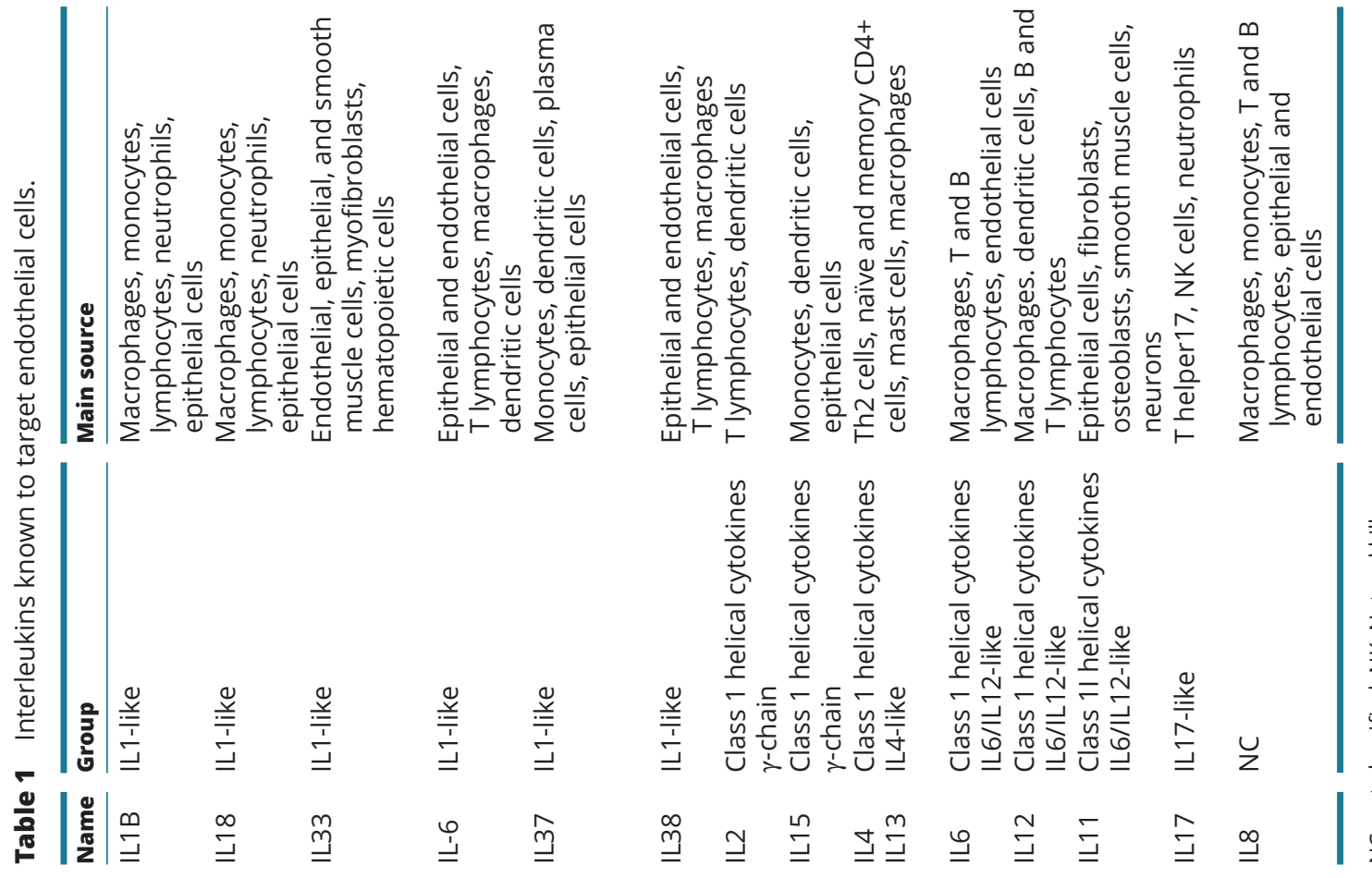


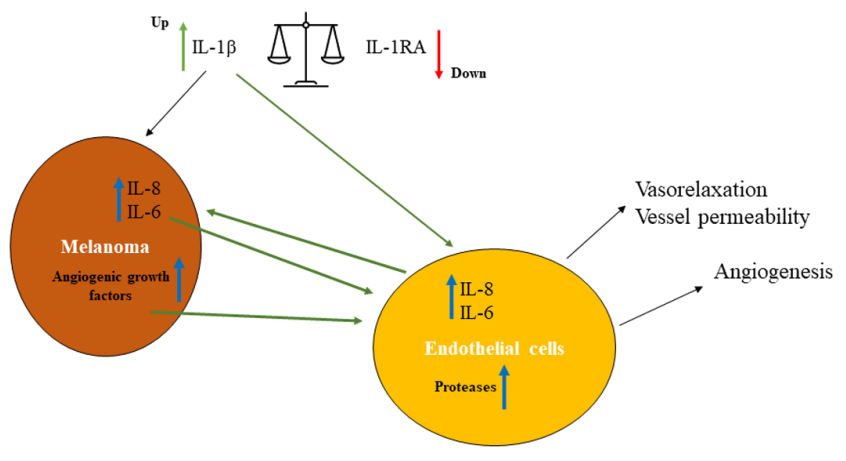

Figure 1

An IL unbalance could be responsible for the tumour angiogenic switch. Differential expression of the pro-inflammatory IL1B in respect to the anti-inflammatory IL1RA could act on melanoma cells, leading to upregulation of angiogenic factors as well as of IL8 and IL6 that, in turn stimulate (green arrows) ECs to produce and secrete additional ILs or proteases, inducing an inflammatory response and tumour angiogenesis.

firstly identified as a chemotactic factor for neutrophils, basophils, and T lymphocytes. IL8 binds with high affinity to two homologous chemokine receptors, CXCR1 (IL8RA) and CXCR2 (IL8RB), activating a signal pathway that involves extracellular signal-regulated kinases (ERK1/2), MAPK, and phosphoinositide 3 kinase. Both receptors are expressed by ECs, at a greater level by microvascular ECs than by larger vessel endothelium, and IL-8 stimulates EC proliferation and chemotaxis as well as capillary tube formation in vitro and angiogenesis in vivo. IL-8 has also a role in blocking EC apoptosis and in augmenting the secretion by ECs of different proteases necessary to modify the basement membrane and the extracellular matrix in the early phases of angiogenesis (19).

ECs are both a direct and indirect target of IL6. ECs do notexpress transmembraneIL6RA, but they can beactivated by IL6 through a trans-signalling pathway that involves the soluble form of IL6RA and the membrane-expressed gp130 receptor subunit (IL6ST) (20). When stimulated with IL6, ECs proliferate and produce inflammatory molecules such as the same IL6 and IL8. IL6 can also induce the expression of angiogenic factors that then act on ECs as well (21). Differently from IL6, acting as a monomer, IL12 acts as a heterodimer, composed of IL12A and IL12B subunit, and signals through a heterodimeric receptor (IL12RB1/ IL12RB2). In 1995, Folkman and colleagues were the first to connect the antitumor and antimetastatic activity of IL12 to its anti-angiogenic properties (22). IL12 inhibits tumour growth by inducing cancer cells to secrete anti-angiogenic factors such as interferon- $\gamma(23)$ and other chemokines that possess angiostatic properties (24).

Since tumour growth strictly depends on oxygen and nutrient supplies and therefore tumour cells are forced to promote tumour angiogenesis, the first utilized therapeutic approach was based on anti-angiogenic compounds such as those against the vascular endothelial growth factor (VEGF)-A and its receptors (18). More recently, an alternative concept has emerged that has the intent to therapeutically target tumour vessels and reported them to normalization. A normal circulation without vessel leakage and tortuosity would improve drug delivery, facilitate immune cell entry into the tumour tissue and the host immune response against cancer cells, and would reduce metastasis dissemination, contrasting tumour cell entry into the vessels (25). Different therapies in this field are under examination in clinical trials. However, these therapies are mostly based on low doses of growth factors, and a possible action of anti-inflammatory ILs, such as IL1RA or IL-2, is not considered. Instead, this possibility should be studied to deep characterize tumorigenesis and propose novel therapeutic approaches.

\section{Psoriasis}

Psoriasis is an autoimmune skin disease with a complex pathogenesis. Even if disease triggers are autoimmune mechanisms and altered inflammatory infiltrates in the tissue, ECs play a role in maintaining the inflammatory context. Vascular enlargement, vessel permeability, EC proliferation appear in the lesional psoriatic skin even before the development of epidermal hyperplasia. ILs have been targets of therapeutic intervention in psoriasis, and IL17A repressors are now actively used in the clinics.

IL-7A receptors IL17RA and IL17RC are expressed on ECs that respond to IL17-stimulation both in vitro and in vivo $(26,27)$. IL17A promotes EC proliferation, migration, and tubule-like vessel formation, as well as the production of inflammatory cytokines. IL17A regulates neutrophil transmigration across the endothelial layer $(28,29)$. In vivo, IL17A promotes angiogenesis indirectly too, through stimulating the production of angiogenic cytokines and chemokines by epithelial cells. IL17A cooperates with TNF in the induction of VEGFA in synovial fibroblasts (30) and in keratinocytes (26).

As shown in Fig. 2, IL17A activates ECs via recruitment of the adaptor ACT1 that can bind to TRAF6, TRAF3, and tumour growth factor $\beta$-activated kinase 1 (TAK1), ending to phosphorylation of either the p38 MAPK (31), ERK1/2, c-Jun N terminal kinase (JNK), or the NFKB pathway (32). IL17A induces EC proliferation by both the MAPK and the NFKB pathways, whereas contributes to the inflammatory phenotype only with NFKB activation (26). Considering that a functional cooperation between IL17A and TNF exists

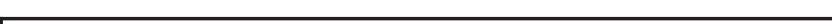

This work is licensed under a Creative Commons Attribution-NonCommercial-NoDerivatives 4.0 International License. ded from Bioscientifica.com at 04/26/2023 09:35:48AM 


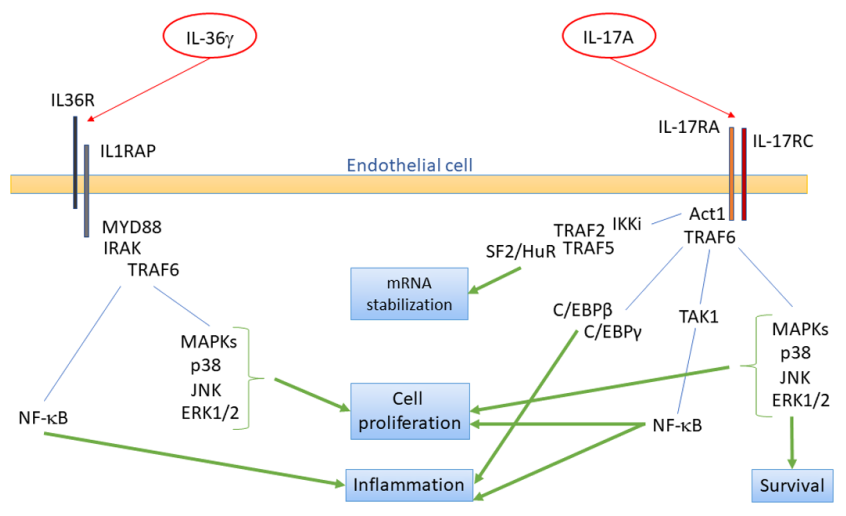

Figure 2

Comparison of IL-36 $\gamma$ and IL17A signalling in ECs. After IL36R binding, IL36y recruits IL1RAP and the adaptor proteins MYD88, TRAF6, IRAK, eventually activating the NFKB and MAPK signalling pathways. In ECS, IL36 $\gamma$ promotes cell proliferation through MAPKs and inflammation through NFxB. IL-17A binds to the heterodimeric receptor complex IL17RA/IL17RC and recruits as adaptor proteins ACT1, TRAF3, TRAF6, TAK1. IL17A-mediated activation of NFKB and/or MAPK pathways induces cell proliferation. Activation of ERK1/2 is involved in cell survival. IL17A can also induce a C/EBP-dependent signalling (32).

in ECs, IL17A is likely capable to induce CCAAT/enhancerbinding protein (CEBP) family members. Indeed, IL17A causes CEBPB phosphorylation in umbilical vein ECs. An additional mechanism involved in the synergistic proinflammatory effects of IL17A and TNF is the stabilization of mRNAs. This is achieved through involvement of a kinase called IKKi, two other adaptors, TRAF2 and TRAF5, and either the mRNA splicing regulatory factor (SF)2 or an RNA-binding protein, human antigen $\mathrm{R}$.

IL17A shares numerous signalling mediators with another group of ILs greatly involved in psoriasis pathogenesis, the IL36 family (33), and it is also a potent inducer of IL36 secretion by different cell types (26). Four different isoforms of IL36 have been identified: IL36A, IL36B, IL36G, having pro-inflammatory functions, and IL36RA, that acts as an anti-inflammatory mediator. IL36 cytokines and IL36R are mainly present in epithelial cells at the organism barrier sites such as skin, respiratory tract, intestines, where they protect the organism from pathogens by activating pro-inflammatory pathways that prompt the antimicrobial activity of immune cells (34). After binding to their receptor, IL36A, IL36B, and IL36G recruit IL1RAP and, subsequently, MyD88, as described above for IL1B, eventually activating the NFKB and MAPK signalling pathway (Fig. 2). Binding of IL36RA to IL36R does not lead to the recruitment of IL1RAP and gives no later signalling. IL36G directly stimulates EC proliferation, mainly through the activation of p38 MAPK, JNKs, and of the ERK1/2 (Fig. 2) (26), whereas IL36G-mediated activation of NFKB leads to an inflammatory phenotype in ECs (26). IL38 does not belong to the IL36 family, but it binds to the same IL36R and has anti-inflammatory activity like that of IL36RA (35). Likewise, IL37, binding to IL18R, prevents the formation of an active receptor complex and triggers intracellular signals that block inflammation (36).

From what is reported above, it is evident that the resolution of the inflammatory status in psoriasis, or in other autoimmune diseases, would require therapeutic action on more than one ILs. This could explain the psoriasis patient's primary and secondary resistance to anti-IL17A treatments observed in the clinics. In the future, combined approaches should be thought. Moreover, having better understood IL signalling mechanisms, a therapeutic intervention on molecules that could block more than one pathogenetic pathway could be considered.

\section{Systemic sclerosis}

Systemic sclerosis (SS) is an autoimmune multi-organ connective tissue disease characterized by the presence of autoantibodies, vasculopathy, inflammation, and fibrosis (37). As SS pathogenesis is poorly understood, it is difficult to identify the trigger cell type between ECs and $\mathrm{T}$ lymphocytes, whereas activation of macrophages and fibroblasts/myofibroblasts is considered to depend upon cytokines secreted by $\mathrm{T}$ cells afterward. In the clinics, onset of SS is represented by initial changes in dermal microcirculation causing damages to the endothelium. Vascular intimal proliferation and remodelling, vasoconstriction, and defective angiogenesis are present (38). These vascular manifestations can precede other disease manifestations by several years.

To improve the understanding of the role of ECs in SS pathogenesis, it is necessary to consider ECs in the context of the tissue in which they are embedded. In fact, interplay of dermal microvascular ECs with skin keratinocytes, fibroblasts, and both innate and adaptive immune cells is extremely important for the development of SS (39). Maehara etal. recently showed that cytotoxic Tlymphocytes accumulate nearby ECs that were upregulating HLA-DR molecules and undergoing apoptosis. Increased apoptosis of other skin cells was also observed as well as production of pro-fibrotic cytokines by $\mathrm{T}$ lymphocytes that could act on both ECs and fibroblasts (40).

A pivotal role for ILs belonging to the IL1 family has been disclosed in the pathogenesis of SS (41). In addition, IL6 and IL17A are now considered as possible therapeutic targets. Indeed, an anti-IL6 receptor antibody, tocilizumab, 
or anti-IL17A antibodies, secukinumab, brodalumab, and ixekizumab, are present in ongoing clinical trials $(42,43)$.

More recently, the IL36 group and IL33 have been considered as possible therapeutic targets.

A functional implication of IL36s in SS has not been directly found so far, but IL36A is considered a profibrotic IL (44). Different from other components of the family, IL33 binds to ST2, a member of the IL1R/Tolllike receptor superfamily. IL33 was initially discovered as a nuclear protein in quiescent ECs where it functions as a transcriptional repressor (45). Upon release, IL33 stimulates ECs, in particular the quiescent ones, inducing inflammation and angiogenesis (46). Therefore, human ECs constitute the major source of IL33 in resting, physiological conditions, and in chronic inflammatory diseases. IL33 is emerging as a major regulator of tissue regulatory $\mathrm{T}$ lymphocytes (45). In SS patients, high serum level of IL33 has been detected and correlates with vascular involvement (47).

It is evident that additional studies are required to clearly understand the implication of the IL36 and IL33 in SS pathogenesis.

An additional IL that should be deeply studied in SS is IL11. This IL is a member of the IL6/IL12-like group, and little is known on a direct effect of IL11 on ECs. IL11 production can be stimulated in ECs by cytomegalovirus infection (48) or by exposure to metal nanoparticles (49). IL11 induces EC migration and vessel formation in vitro and angiogenesis in vivo (50). IL11 is upregulated in SS, but no data have been reported on its contribution to the vasculopathy typical of this disease (51).

\section{Viral infection severe acute respiratory syndrome coronavirus 2 (SARS-CoV-2)-mediated vascular inflammation}

These recent years have seen subsequent outbreak of viral infections, starting from the H1N1 influenza in 2009 up to nowadays with the SARS-CoV-2 pandemic. These viral infections culminate with an acute respiratory distress syndrome, characterized by diffuse alveolar damage with perivascular $\mathrm{T}$ lymphocyte infiltration and by widespread thrombosis with microangiopathy (52). Further specific analysis of SARS-CoV-2-infected lungs has underlined the presence of angiogenesis, mainly through the intussusceptive mechanism, the existence of the virus into ECs as well as in the extracellular space, and the expression of several angiogenesis-related genes, some of them specifically induced in SARS-CoV-2infected lungs in respect to H1N1-infected samples. These data emphasize the role of ECs themselves in vascular dysfunction, thrombosis, and inflammation associated with SARS-CoV-2 infection (53). It is not clear so far in which part EC activation is due to direct viral infection, and in which one to leukocyte- or epithelial cell-mediated activation and secretion of inflammatory cytokines. This aspect deserves additional investigations to better address therapeutic treatments.

As reported in Fig. 3, ECs express the angiostatinconverting enzyme 2 (ACE2), the main receptor of SARSCoV-2, and the transmembrane protease serine 2, necessary to cleave the viral spike protein and permit the virus to enter the cell (53). ACE2 is part of the renin/angiotensin system, and it is involved in cardiovascular homeostasis by controlling blood pressure and promoting vasodilation. ACE2 expression is reduced in older individuals and in patients with cardiovascular disease, two groups that are at high risk to develop severe syndromes upon SARSCoV-2 infection. For this reason, presence of additional receptors has been investigated. Indeed, the two identified alternative receptors, neuropilin-1 and CD209L, are also highly expressed in ECs $(53,54)$.

Neuropilin-1 binds to the spike viral protein and mediates viral entry into different tissues. Neuropilin-1 is a semaphorin receptor involved in neuron guidance and can mediate virus access to the CNS. Neuropilin- 1 is also a co-receptor for selected isoforms of the VEGF family and is highly involved in the angiogenesis process. Infected ECs augment membrane expression of neuropilin-1 further

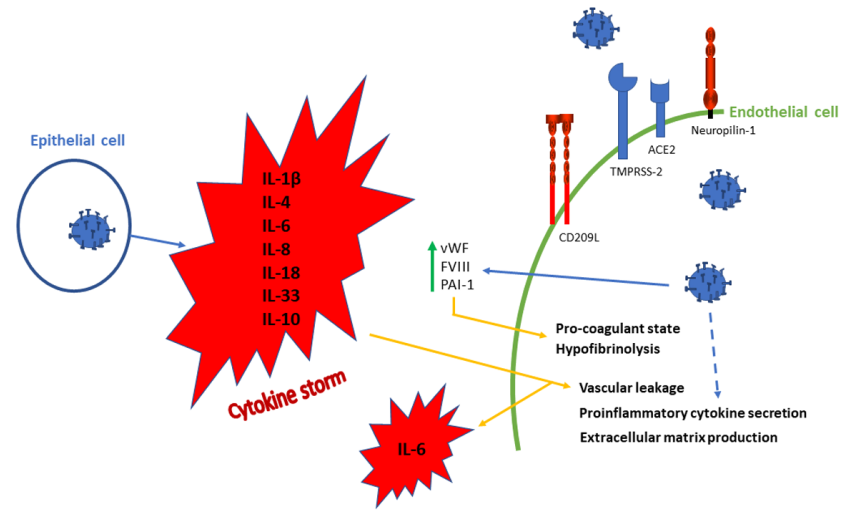

Figure 3

SARS-CoV-2 infection and ECS. ECS are the main characters of the vascular disfunctions that characterized viral infection and that are represented by capillary leak, a pro-coagulant state, and hypo fibrinolysis (53). In fact, ECs are the target of the 'cytokine storm' produced by viral-infected lung epithelial cells and by associated immune cells. The IL types identified in the 'cytokine storm' are indicated. It is not clear so far in which part EC activation is due to direct viral infection (ECs express every known SARS-CoV-2 receptor) (54), and in which one to leukocyte- or epithelial cell-mediated activation and secretion of these inflammatory cytokines.

This work is licensed under a Creative Commons Attribution-NonCommercial-NoDerivatives 4.0 International License. ded from Bioscientifica.com at 04/26/2023 09:35:48AM 
enhancing viral infection, vasodilation, and angiogenesis (54). Interestingly, neuropilin-1 has not been effectively considered so far as a therapeutic target to block viral infection and the related angiopathies.

CD209L is a C-type lectin transmembrane glycoprotein involved in carbohydrate and protein binding. CD209L physiological role is to mediate cell-cell adhesion by acting as a high affinity receptor for intercellular adhesion molecule 2 and 3. Highly expressed in alveolar epithelial cells and in the ECs of lung and kidney, CD209L binds to the spike protein of SARS-Cov-2 (54). Once infected, ECs switch to a pro-coagulant state by increasing the production of von Willebrand factor and factor VIII, which participate in clot formation, and the expression of plasminogen activator inhibitor 1 , which blocks plasminogen conversion into plasmin and clot degradation. CD209Ltargeting molecules have not been used in therapeutic protocols, and additional trials are required to validate this kind of treatment in viral-infected patients.

The most remarkable aspect connected with the action of ILs on ECs during viral infection is the cytokine release syndrome, also known as the 'cytokine storm,' elicited by SARS-CoV-2 infection as well as by some drugs, sepsis, or cancers, and characterized by a major increase of proinflammatory cytokines in the circulation and in the bronchoalveolar fluid (55). A rapid, wellorganized, and controlled innate immune response is the first defence against viral infection. However, when this immune response is unbalanced, it will cause damage and organ failure. In fact, rapid increase of chemokine and cytokine secretion by infected lung epithelial cells attracts inflammatory cells such as neutrophils and monocytes, resulting in excessive infiltration of immune cells in the tissue, additional cytokine secretion, and lung injury. Different proinflammatory ILs participate in the SARS-CoV-2-induced 'cytokine storm': IL1B, IL4, IL6, IL8, IL18, and IL33 have been isolated. Augmented secretion of the inflammatory inhibitor IL10 was also observed (55), probably an attempt of the host tissue to block the virus-mediated inflammation. Most of these ILs cause endothelial fenestration and vascular leakage as well as production of excessive extracellular matrix, angiogenesis, and secretion of supplementary inflammatory ILs, especially IL6 (Fig. 3). Indeed, changes in circulating IL6 amounts and, even more, in the IL6/IL10 ratio, predict outcomes in SARS-CoV-2-infected patients (56). Thus, it is evident why IL6 is considered a potential therapeutic target for the treatment of SARS-CoV-2-infected patients (57). Tocilizumab is a humanized MAB against IL6 receptors, usually employed for rheumatoid arthritis treatment, that can block both the IL6 classic and the trans-signalling pathway. At least two studies have shown clinical improvement in SARS-CoV-2-infected patients treated with tocilizumab, with an important recovery of oxygen supplement and reduced fever. Therapy with tocilizumab at an early stage of the disease reduces the mortality rate of the infection (57). However, IL6 blockade could reduce host immune responses against the virus, and the timing of IL6 administration needs to be carefully considered. Other IL6 antagonists, sarilumab and siltuximab, have been approved for treatment of either rheumatologic pathologies or for the lymphoproliferative Castleman's disorder. These therapeutic agents have demonstrated to be effective also in SARS-CoV-2 infection (57), but additional trials are required before they could be safely used in the clinics.

An inflammatory circuit that needs further investigation in respect to viral infection is the IL36, described above for autoimmune diseases such as psoriasis and SS. At present, no definitive data are available to understand whether IL36 could have a protective role, boosting the host immune response, or a detrimental one, contributing to amplifying the 'cytokine storm.' IL36 was first characterized in mouse keratinocytes after infection with herpes simplex virus type 1 , but influenza viruses can also stimulate the release of IL36 by epithelial cells. IL36G is upregulated in the lung following H1N1 infection and has a protective role, stimulating macrophage activation (58). However, IL36 are also potent inducers of inflammatory cytokines such as IL6 and may augment the inflammatory status. So far, only indirect evidence is reported on expression of IL36 in SARS-CoV-2 infected patients (59). It should be also considered that IL36 is highly expressed in the lungs of allergic and asthma-affected patients, but studies have shown that asthma is not a risk factor in SARS-CoV-2-infected patients (60). Therefore, there is the possibility that IL36 inflammatory circuit contributes to protect patients with asthma against detrimental outcomes of SARS-CoV-2 infection.

\section{Conclusions}

Contrasting data have been obtained for the effects of ILs in vascular inflammation. ILs can act as pro- or antiangiogenic molecules depending on the different context examined, such as normal vs tumour cells, or on the specific tissue or pathological situation considered. This could be due to the amount of pro- or anti-inflammatory ILs produced by different cell types or by ECs themselves. 
Moreover, ILs strictly interconnect one another, with feedback regulation mechanisms that aim at reducing the inflammatory state. Such interconnections make it difficult to introduce a specific anti-IL therapy in inflammatory diseases, and often therapy side effects can be even more damaging than the treatment itself. Therefore, the relative quantities of pro- and antiinflammatory and angiogenic ILs should be always examined in the different pathological situations prior to properly act with an IL-based therapy.

Timely immune responses and punctual signal transduction are fundamental to avoid vascular chronic inflammation and long-term damage. This aspect is particularly evident in the SARS-CoV-2 infection where an excessive immune response with the so-called 'cytokine storm' seems to be the leading cause of vascular dysfunction and fatal thrombosis. Likewise, timely and punctual therapeutic intervention should be considered when using IL-based treatment approaches.

In conclusion, despite ILs have been studied for years, deeper and deeper knowledge of IL role and crosstalk is still necessary to lead us to disclose and apply novel IL-based therapies.

\section{Declaration of interest}

The authors declare that there is no conflict of interest that could be perceived as prejudicing the impartiality of this review.

\section{Funding}

This work was supported by the Italian Ministry of Health Ricerca Corrente 2018-2020, RC2.2. M L C has been the recipient of a Fondazione Veronesi fellowship.

\section{Author contribution statement}

$M L C$ wrote the paper and took care of literature research and figures. C M $\mathrm{F}$ conceived the study and wrote the paper.

\section{Acknowledgements}

M L C wishes to thank Fondazione Veronesi for supporting her Research work with a fellowship.

\section{References}

1 Brocker C, Thompson D, Matsumoto A, Nebert DW \& Vasiliou V. Evolutionary divergence and functions of the human interleukin
(IL) gene family. Human Genomics 20105 30-55. (https://doi. org/10.1186/1479-7364-5-1-30)

2 Barksby HE, Lea SR, Preshaw PM \& Taylor JJ. The expanding family of interleukin-1 cytokines and their role in destructive inflammatory disorders. Clinical and Experimental Immunology 2007149 217-225. (https://doi.org/10.1111/j.1365-2249.2007.03441.x)

3 Clancy DM, Sullivan GP, Moran HBT, Henry CM, Reeves EP, McElvaney NG, Lavelle EC \& Martin SJ. Extracellular neutrophil proteases are efficient regulators of IL-1, IL-33, and IL-36 cytokine activity but poor effectors of microbial killing. Cell Reports 201822 2937-2950. (https://doi.org/10.1016/j.celrep.2018.02.062)

4 Rochman Y, Spolski R \& Leonard WJ. New insights into the regulation of T cells by $\mathrm{y}_{\mathrm{c}}$ family cytokines. Nature Reviews: Immunology 20099 480-490. (https://doi.org/10.1038/nri2580)

5 Heinrich PC, Behrmann I, Haan S, Hermanns HM, Muller-Newen G \& Schaper F. Principles of interleukin (IL)-6-type cytokine signalling and its regulation. Biochemical Journal 2003374 1-20. (https://doi. org/10.1042/BJ20030407)

6 Trinchieri G, Pflanz S \& Kastelein RA. The IL-12 family of heterodimeric cytokines: new players in the regulation of $\mathrm{T}$ cell responses. Immunity 2003 19 641-644. (https://doi.org/10.1016/s10747613(03)00296-6)

7 Kotenko SV, Gallagher G, Baurin VV, Lewis-Antes A, Shen M, Shah NK, Langer JA, Sheikh F, Dickensheets H \& Donnelly RP. IFN-lambdas mediate antiviral protection through a distinct class II cytokine receptor complex. Nature Immunology 20034 69-77. (https://doi. org/10.1038/ni875)

8 Cua DJ \& Tato CM. Innate IL-17-producing cells: the sentinels of the immune system. Nature Reviews: Immunology 201010 479-489. (https://doi.org/10.1038/nri2800)

9 Gaffen SL. Structure and signalling in the IL-17 receptor family. Nature Reviews: Immunology 20099 556-567. (https://doi.org/10.1038/nri2586)

10 Hernandez-Segura A, Nehme J \& Demaria M. Hallmarks of cellular senescence. Trends in Cell Biology 201828 436-453. (https://doi. org/10.1016/j.tcb.2018.02.001)

11 Kuilman T, Michaloglou C, Vredeveld LC, Douma S, van Doorn R, Desmet CJ, Aarden LA, Mooi WJ \& Peeper DS. Oncogene-induced senescence relayed by an interleukin-dependent inflammatory network. Cell 2008133 1019-1031. (https://doi.org/10.1016/j. cell.2008.03.039)

12 Ting KK, Coleman P, Zhao Y, Vadas MA \& Gamble JR. The aging endothelium. Vascular Biology 20213 R35-R47. (https://doi. org/10.1530/VB-20-0013)

13 Gabay C, Lamacchia C \& Palmer G. IL-1 pathways in inflammation and human diseases. Nature Reviews: Rheumatology 20106 232-241. (https://doi.org/10.1038/nrrheum.2010.4)

14 Béguin EP, van den Eshof BL, Hoogendijk AJ, Nota B, Mertens K, Meijer $\mathrm{AB} \&$ van den Biggelaar M. Integrated proteomic analysis of tumor necrosis factor $\alpha$ and interleukin $1 \beta$-induced endothelial inflammation. Journal of Proteomics 2019192 89-101. (https://doi. org/10.1016/j.jprot.2018.08.011)

15 John A, Günes C \& Bolenz C, Vidal-Y-Sy S, Bauer AT, Schneider SW \& Gorzelanny C, et al. Bladder cancer-derived interleukin-1 converts the vascular endothelium into a pro-inflammatory and pro-coagulatory surface. BMC Cancer 202020 1178. (https://doi.org/10.1186/s12885020-07548-z)

16 Strozyk EA, Desch A, Poeppelmann B, Magnolo N, Wegener J, Huck V \& Schneider SW. Melanoma-derived IL-1 converts vascular endothelium to a proinflammatory and procoagulatory phenotype via NFkB activation. Experimental Dermatology 201423 670-676. (https:// doi.org/10.1111/exd.12505)

17 Bridgewood C, Stacey M, Alase A, Lagos D, Graham A \& Wittmann M. IL-36g has proinflammatory effects on human endothelial cells. Experimental Dermatology 201726 402-408. (https://doi.org/10.1111/ exd.13228) (c) 2020 The authors Published by Bioscientifica Ltd
This work is licensed under a Creative Commons Attribution-NonCommercial-NoDerivatives 4.0 International License. ind from Bioscientifica com at 04/26/2023 09:35:48AM 
18 Folkman J. Angiogenesis in cancer, vascular, rheumatoid and other disease. Nature Medicine 19951 27-31. (https://doi.org/10.1038/ nm0195-27)

19 Brat DJ, Bellail AC \& Van Meir EG. The role of interleukin-8 and its receptors in gliomagenesis and tumoral angiogenesis. Neuro-Oncology 20057 122-133. (https://doi.org/10.1215/S1152851704001061)

20 Hou T, Tieu BC, Ray S, Recinos A, Cui R, Tilton RG \& Brasier AR. Roles of IL-6-gp130 signaling in vascular inflammation. Current Cardiology Reviews 20084 179-192. (https://doi. org/10.2174/157340308785160570)

21 Failla CM, Odorisio T, Cianfarani F, Schietroma C, Puddu P $\&$ Zambruno G. Placenta growth factor is induced in human keratinocytes during wound healing. Journal of Investigative Dermatology 2000115 388-395. (https://doi.org/10.1046/j.15231747.2000.00085.x)

22 Voest EE, Kenyon BM, O'Reilly MS, Truitt G, D'Amato RJ \& Folkman J. Inhibition of angiogenesis in vivo by interleukin 12. Journal of the National Cancer Institute 199587 581-586. (https://doi.org/10.1093/ jnci/87.8.581)

23 Del Vecchio M, Bajetta E, Canova S, Lotze MT, Wesa A, Parmiani G \& Anichini A. Interleukin-12: biological properties and clinical application. Clinical Cancer Research 200713 4677-4685. (https://doi. org/10.1158/1078-0432.CCR-07-0776)

24 Airoldi I \& Ribatti D. Regulation of angiostatic chemokines driven by IL-12 and IL-27 in human tumors. Journal of Leukocyte Biology 201190 875-882. (https://doi.org/10.1189/jlb.0511237)

25 Ganss R. Tumour vessel remodelling: new opportunities in cancer treatment. Vascular Biology 20202 R35-R43. (https://doi.org/10.1530/ VB-19-0032)

26 Mercurio L, Failla CM, Capriotti L, Scarponi C, Facchiano F, Morelli M, Rossi S, Pagnanelli G, Albanesi C, Cavani A, et al. Interleukin (IL)-17/ IL-36 axis participates to the crosstalk between endothelial cells and keratinocytes during inflammatory skin responses. PLOS ONE 202015 e0222969. (https://doi.org/10.1371/journal.pone.0222969)

27 Mercurio L, Morelli M, Scarponi C, Eisenmesser EZ, Doti N, Pagnanelli G, Gubinelli E, Mazzanti C, Cavani A, Ruvo M, et al. IL38 has an anti-inflammatory action in psoriasis and its expression correlates with disease severity and therapeutic response to antiIL-17A treatment. Cell Death and Disease 20189 1104. (https://doi. org/10.1038/s41419-018-1143-3)

28 Bosteen MH, Tritsaris K, Hansen AJ \& Dissing S. IL-17A potentiates TNFa-induced secretion from human endothelial cells and alters barrier functions controlling neutrophils rights of passage. Pflügers Archiv: European Journal of Physiology 2014466 961-972. (https://doi org/10.1007/s00424-013-1354-5)

29 Yuan S, Zhang S, Zhuang Y, Zhang H, Bai J \& Hou Q. Interleukin-17 stimulates STAT3-mediated endothelial cell activation for neutrophil recruitment. Cellular Physiology and Biochemistry 201536 2340-2356. (https://doi.org/10.1159/000430197)

30 Honorati MC, Neri S, Cattini L \& Facchini A. Interleukin-17, a regulator of angiogenic factor release by synovial fibroblasts. Osteoarthritis and Cartilage 200614 345-352. (https://doi. org/10.1016/j.joca.2005.10.004)

31 Mai J, Nanayakkara G, Lopez-Pastrana J, Li X, Li YF, Wang X, Song A, Virtue A, Shao Y, Shan H, et al. Interleukin-17A promotes aortic endothelial cell activation via transcriptionally and posttranslationally activating p38 mitogen-activated protein kinase (MAPK) pathway. Journal of Biological Chemistry 2016291 4939-4954. (https://doi.org/10.1074/jbc.M115.690081)

32 Amatya N, Garg AV \& Gaffen SL. IL-17 signaling: the yin and the yang Trends in Immunology 201738 310-322. (https://doi.org/10.1016/j. it.2017.01.006)

33 Madonna S, Girolomoni G, Dinarello CA \& Albanesi C. The significance of IL-36 hyperactivation and IL-36R targeting in psoriasis International Journal of Molecular Sciences 201920 e3318. (https://doi. org/10.3390/ijms20133318)
34 Buhl AL \& Wenzel J. Interleukin-36 in infectious and inflammatory skin diseases. Frontiers in Immunology 201910 1162. (https://doi. org/10.3389/fimmu.2019.01162)

35 van de Veerdonka FL, Stoeckmanc AK, Wuc G, Boeckermannc AN, Azama T, Neteab MG, Joosten LA, van der Meer JW, Hao R, Kalabokis V, et al. IL-38 binds to the IL-36 receptor and has biological effects on immune cells similar to IL-36 receptor antagonist. PNAS 2012109 3001-3005. (https://doi.org/10.1073/pnas.1121534109)

36 Boutet MA, Nerviani A \& Pitzalis C. IL-36, IL-37, and IL-38 cytokines in skin and joint inflammation: a comprehensive review of their therapeutic potential. International Journal of Molecular Sciences 2019 20 1257. (https://doi.org/10.3390/ijms20061257)

37 Denton CP \& Khanna D. Systemic sclerosis. Lancet 2017390 1685-1699. (https://doi.org/10.1016/S0140-6736(17)30933-9)

38 Ota Y \& Kuwana M. Endothelial cells and endothelial progenitor cells in the pathogenesis of systemic sclerosis. European Journal of Rheumatology 20207 S139-S146. (https://doi.org/10.5152/eurjrheum.2019.19158)

39 Asano Y, Takahashi T \& Saigusa R. Systemic sclerosis: is the epithelium a missing piece of the pathogenic puzzle? Journal of Dermatological Science 201994 259-265. (https://doi.org/10.1016/j. jdermsci.2019.04.007)

40 Maehara T, Kaneko N, Perugino CA, Mattoo H, Kers J, AllardChamard H, Mahajan VS, Liu H, Murphy SJ, Ghebremichael M et al. Cytotoxic CD4+ T lymphocytes may induce endothelial cell apoptosis in systemic sclerosis. Journal of Clinical Investigation 2020130 2451-2464. (https://doi.org/10.1172/JCI131700)

$41 \mathrm{Xu}$ D, Mu R \& Wei X. The role of IL-1 family cytokines in the pathogenesis of systemic sclerosis. Frontiers in Immunology $2019 \mathbf{1 0}$ 2025. (https://doi.org/10.3389/fimmu.2019.02025)

42 Shima Y. The benefits and prospects of interleukin- 6 inhibitor on systemic sclerosis. Modern Rheumatology 201929 294-301. (https://doi. org/10.1080/14397595.2018.1559909)

43 Rafael-Vidal C, Perez N, Altabas I, Garcia S \& Pego-Reigosa JM. Blocking IL-17: a promising strategy in the treatment of systemic rheumatic diseases. International Journal of Molecular Sciences 2020217100. (https://doi.org/10.3390/ijms21197100)

44 Chi HH, Hua KF, Lin YC, Chu CL, Hsieh CY, Hsu YJ, Ka SM, Tsai YL, Liu FC \& Chen A. IL-36 signaling facilitates activation of the NLRP3 inflammasome and IL-23/IL-17 axis in renal inflammation and fibrosis. Journal of the American Society of Nephrology 201728 2022-2037. (https://doi.org/10.1681/ASN.2016080840)

45 Cayrol C \& Girard JP. Interleukin-33 (IL-33): a nuclear cytokine from the IL-1 family. Immunological Reviews 2018281 154-168. (https://doi. org/10.1111/imr.12619)

46 Pollheimer J, Bodin J, Sundnes O, Edelmann RJ, Skanland SS, Sponheim J, Brox MJ, Sundlisaeter E, Loos T, Vatn M, et al. Interleukin-33 drives a proinflammatory endothelial activation that selectively targets nonquiescent cells. Arteriosclerosis, Thrombosis, and Vascular Biology 201333 e47-e55. (https://doi.org/10.1161/ ATVBAHA.112.253427)

47 Manetti M, Guiducci S, Ceccarelli C, Romano E, Bellando-Randone S, Conforti ML, Ibba-Manneschi L \& Matucci-Cerinic M. Increased circulating levels of interleukin 33 in systemic sclerosis correlate with early disease stage and microvascular involvement. Annals of the Rheumatic Diseases 201170 1876-1878. (https://doi.org/10.1136/ ard.2010.148247)

48 Gustafsson KLR, Renné T, Söderberg-Naucler C \& Butler LM. Human cytomegalovirus replication induces endothelial cell interleukin-11. Cytokine 2018111 563-566. (https://doi.org/10.1016/j. cyto.2018.05.018)

49 Jang J, Park S \& Choi IH. Increased interleukin-11 and stress-related gene expression in human endothelial and bronchial epithelial cells exposed to silver nanoparticles. Biomolecules 202111 234. (https://doi. org/10.3390/biom11020234)

50 Elshabrawy HA, Volin MV, Essani AB, Chen Z, McInnes IB, Van Raemdonck K, Palasiewicz K, Arami S, Gonzalez M, Ashour HM,

This work is licensed under a Creative Commons Attribution-NonCommercial-NoDerivatives 4.0 International License. ded from Bioscientifica.com at 04/26/2023 09:35:48AM 
et al. IL-11 facilitates a novel connection between RA joint fibroblasts and endothelial cells. Angiogenesis 201821 215-228. (https://doi. org/10.1007/s10456-017-9589-y)

51 Cook SA \& Schafer S. Hiding in plain sight: interleukin-11 emerges as a master regulator of fibrosis, tissue integrity, and stromal inflammation. Annual Review of Medicine 202071 263-276. (https:// doi.org/10.1146/annurev-med-041818-011649)

52 Ackermann M, Verleden SE, Kuehnel M, Haverich A, Welte T, Laenger F, Vanstapel A, Werlein C, Stark H, Tzankov A, et al. Pulmonary vascular endothelialitis, thrombosis, and angiogenesis in Covid-19. New England Journal of Medicine 2020383 120-128. (https://doi. org/10.1056/NEJMoa2015432)

53 Pons S, Fodil S, Azoulay E \& Zafrani L. The vascular endothelium: the cornerstone of organ dysfunction in severe SARS-CoV-2 infection. Critical Care 202024 353. (https://doi.org/10.1186/s13054-020-03062-7)

54 Giordo R, Paliogiannis P, Mangoni AA \& Pintus G. SARS-CoV-2 and endothelial cell interaction in COVID-19: molecular perspectives. Vascular Biology 20213 R15-R23. (https://doi.org/10.1530/VB-20-0017)

55 Ye Q, Wang B \& Mao J. The pathogenesis and treatment of the 'cytokine storm' in COVID-19. Journal of Infection 202080 607-613. (https://doi.org/10.1016/j.jinf.2020.03.037)
56 McElvaney OJ, Hobbs BD, Qiao D, McElvaney OF, Moll M, McEvoy NL, Clarke J, O'Connor E, Walsh S, Cho MH, et al. A linear prognostic score based on the ratio of interleukin- 6 to interleukin-10 predicts outcomes in COVID-19. EBiomedicine 202061 103026. (https://doi.org/10.1016/j. ebiom.2020.103026)

57 Khaedir Y \& Kartika R. Perspectives on targeting IL-6 as a potential therapeutic strategy for COVID-19. Journal of Interferon and Cytokine Research 202141 37-43. (https://doi.org/10.1089/ jir.2020.0135)

58 Wein AN, Dunbar PR, McMaster SR, Li ZT, Denning TL \& Kohlmeier JE. IL-36g protects against severe influenza infection by promoting lung alveolar macrophage survival and limiting viral replication. Journal of Immunology 2018201 573-582. (https://doi.org/10.4049/ jimmunol.1701796)

59 Wang X, Yi P \& Liang Y. The role of IL-36 in infectious diseases: potential target for COVID-19? Frontiers in Immunology 202112 662266. (https://doi.org/10.3389/fimmu.2021.662266)

60 Liuzzo Scorpo M, Ferrante G \& La Grutta S. An overview of asthma and Covid-19: protective factors against SARS-COV-2 in pediatric patients. Frontiers in Pediatrics 20219 661206. (https://doi.org/10.3389/ fped.2021.661206)

Received in final form 18 August 2021

Accepted 18 October 2021

Accepted Manuscript published online 18 October 2021 (c) 2020 The authors Published by Bioscientifica Ltd
This work is licensed under a Creative Commons Attribution-NonCommercial-NoDerivatives 4.0 International License. 